\title{
Nomimicins B-D, new tetronate-class polyketides from a marine-derived actinomycete of the genus Actinomadura
}

\author{
Zhiwei Zhang ${ }^{1}$, Tao Zhou ${ }^{1}$, Taehui Yang ${ }^{2, \S}$, Keisuke Fukaya ${ }^{1}$, Enjuro Harunari ${ }^{1}$, \\ Shun Saito ${ }^{1,9}$, Katsuhisa Yamada ${ }^{3}$, Chiaki Imada ${ }^{2}$, Daisuke Urabe ${ }^{1}$ \\ and Yasuhiro Igarashi ${ }^{* 1}$
}

\section{Full Research Paper}

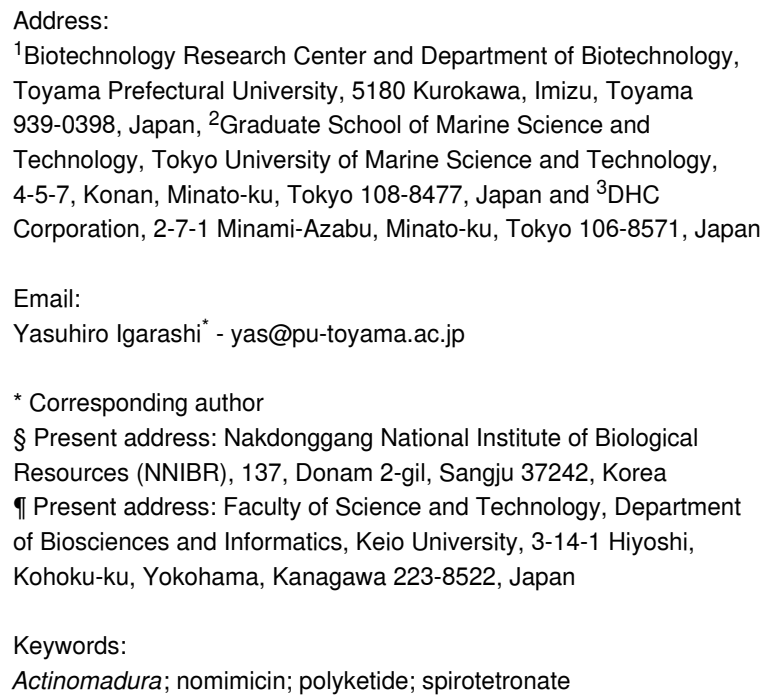

\author{
Beilstein J. Org. Chem. 2021, 17, 2194-2202. \\ https://doi.org/10.3762/bjoc.17.141 \\ Received: 01 July 2021 \\ Accepted: 11 August 2021 \\ Published: 27 August 2021 \\ Associate Editor: J. S. Dickschat \\ (c) 2021 Zhang et al.; licensee Beilstein-Institut. \\ License and terms: see end of document.
}

\begin{abstract}
Three new tetronate-class polyketides, nomimicins B, C, and D, along with nomimicin, hereafter named nomimicin A, were isolated from the culture extract of Actinomadura sp. AKA43 collected from floating particles in the deep-sea water of Sagami Bay, Japan. The structures of nomimicins B, C, and D were elucidated through the interpretation of NMR and MS analytical data, and the absolute configuration was determined by combination of NOESY/ROESY and ECD analyses. Nomimicins B, C, and D showed antimicrobial activity against Gram-positive bacteria, Kocuria rhizophila and Bacillus subtilis, with MIC values in the range of 6.5 to $12.5 \mu \mathrm{g} / \mathrm{mL}$. Nomimicins B and C also displayed cytotoxicity against P388 murine leukemia cells with $\mathrm{IC}_{50}$ values of 33 and $89 \mu \mathrm{M}$, respectively.
\end{abstract}

\section{Introduction}

Actinomycetes are a valuable source of bioactive compounds, accounting for approximately two thirds of all known antibiotics, and more than $70 \%$ of them are produced by the genus
Streptomyces [1]. However, intensive and concentrated screening activities on soil actinomycetes resulted in the repeated isolation of known compounds [2], which conse- 
quently prompted the exploration of untouched niches, such as extreme environments [3]. The marine environment is now attracting attention as a promising source for actinomycetes potentially producing new secondary metabolites $[4,5]$. Indeed, a large number of pharmaceutically worthy new compounds has been found from marine actinomycetes in various niches including sediments, sea water, marine plants, and marine invertebrates [6-8]. In the past 20 years, our laboratory studied the actinomycetes collected from the deep sea water (DSW) of the Sea of Japan and discovered diverse classes of bioactive compounds, such as lydicamycin congeners, $\gamma$-butyrolactones, and nyuzenamides [9-11], whereas DSW in other sea areas had not been studied, although a total of 15 DSW pumping stations are operated in Japan. We recently carried out metagenomic analysis of DSW using DGGE and pyrosequencing techniques and revealed that the bacterial community structure in DSW was varied depending on the collection sites [12]. Furthermore, we found that the DSW of Sagami Bay (Pacific Ocean side of Honshu Island, Japan) contained more unknown actinomycete species than other sea areas, which eventually led to the discovery of akazamicin, a new cytotoxic aromatic polyketide from Nonomuraea [13] and akazaoxime, an antibacterial oxime derivative from Micromonospora [14]. Along the lines of these previous studies, metabolite analysis of actinomycetes from the DSW of Sagami Bay was further conducted, and three new tetronate-class polyketides, nomimicins B (1), C (2), and D (3) were found from a rare actinomycete of the genus Actinomadura. We herein describe the isolation, structure determination, and biological activities of 1-3.

\section{Results and Discussion}

The producing strain Actinomadura sp. AKA43 was isolated from DSW collected at a depth of $-800 \mathrm{~m}$ in Sagami Bay, Japan. Strain AKA43 was cultured in A16 medium, and the whole culture broth was extracted with 1-butanol. The extract was subjected to silica gel and ODS column chromatography, and the final purification was achieved by reversed-phase HPLC to yield two new spirotetronate polyketides, nomimicins B (1) and C (2), along with a known compound, nomimicin A (4) [15]. From the extract of the fermentation broth cultured in A $11 \mathrm{M}$ medium, an additional new tetronate polyketide nomimicin D (3), was isolated (Figure 1).

Nomimicin B (1) was obtained as a colorless amorphous solid. The molecular formula was determined to be $\mathrm{C}_{30} \mathrm{H}_{40} \mathrm{O}_{8}$, based on the HRESITOFMS analysis $\left([\mathrm{M}+\mathrm{Na}]^{+} \mathrm{m} / z\right.$ 551.2612, $\Delta-0.3 \mathrm{mmu})$. Structural analogy between $\mathbf{1}$ and $\mathbf{4}$ was suggested by the global similarity of the UV and NMR spectra between the compounds. In the ${ }^{13} \mathrm{C}$ NMR spectrum, four nonprotonated carbons assignable to the tetronic acid moiety were detected at $\delta_{C} 108.2,170.4,200.7$, and 204.5. In addition,

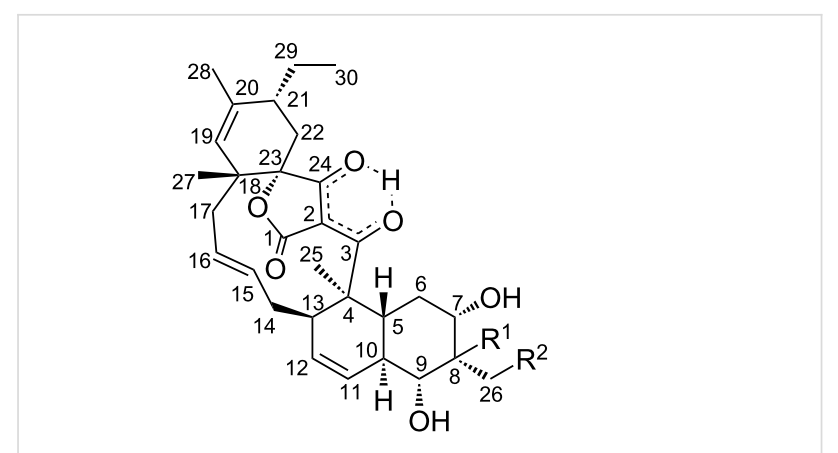

nomimicin $B(\mathbf{1}): \mathrm{R}^{1}=\mathrm{R}^{2}=\mathrm{OH}$

nomimicin $\mathrm{C}(\mathbf{2}): \mathrm{R}^{1}=\mathrm{OH}, \mathrm{R}^{2}=\mathrm{H}$ nomimicin $A(4): R^{1}=R^{2}=H$

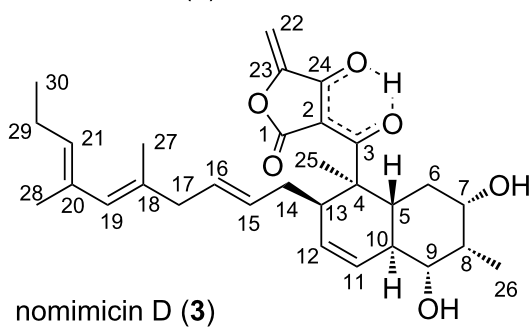

Figure 1: Structures of nomimicins A-D (4 and 1-3).

${ }^{13} \mathrm{C}$ NMR and HSQC analyses revealed the presence of six $\mathrm{sp}^{2}$ carbon atoms (five are proton-bearing), two quaternary $\mathrm{sp}^{3}$ carbon atoms, two oxygen-bearing nonprotonated carbon atoms, six $\mathrm{sp}^{3}$ methine groups (two are oxygenated), six $\mathrm{sp}^{3}$ methylene moieties, and four methyl groups (Table 1). COSY analysis clarified two carbon chains (Figure 2). The first one, spanning from $\mathrm{H} 7$ to $\mathrm{H} 17$, contained an oxymethine (H9) branching at $\mathrm{C} 10$, a cis-configured double bond between $\mathrm{C} 11$ and $\mathrm{C} 12$ $\left({ }^{3} J_{\mathrm{H} 11, \mathrm{H} 12}=10.0 \mathrm{~Hz}\right)$, and a trans-double bond between $\mathrm{C} 15$ and $\mathrm{C} 16\left({ }^{3} J_{\mathrm{H} 15, \mathrm{H} 16}=14.8 \mathrm{~Hz}\right)$. Placement of the oxygenated carbon atom $\mathrm{C} 8$ between $\mathrm{C} 7$ and $\mathrm{C} 9$ and the attachment of the oxygenated methylene carbon atom $\mathrm{C} 26$ to $\mathrm{C} 8$ were deduced from the $\mathrm{HMBC}$ correlations from $\mathrm{H} 7$ and $\mathrm{H} 9$ to $\mathrm{C} 8$ and $\mathrm{C} 26$ and from $\mathrm{H} 26$ to $\mathrm{C} 7, \mathrm{C} 8$, and $\mathrm{C}$, thereby establishing a highly oxygenated cyclohexane ring. This six-membered ring was

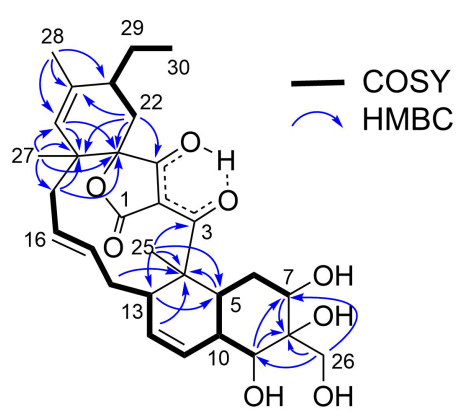

Figure 2: COSY and key HMBC correlations for 1. 
Table 1: ${ }^{1} \mathrm{H}$ and ${ }^{13} \mathrm{C}$ NMR data for nomimicins $\mathrm{B}(\mathbf{1})$ and $\mathrm{C}(\mathbf{2})$

\begin{tabular}{|c|c|c|c|c|c|c|}
\hline \multirow[b]{2}{*}{ atom no. } & \multicolumn{3}{|c|}{ nomimicin B (1) } & \multicolumn{3}{|c|}{ nomimicin C (2) } \\
\hline & $\delta_{C}^{a}$ & $\delta_{\mathrm{H}}$, mult $(J \text { in } \mathrm{Hz})^{\mathrm{b}}$ & $\mathrm{HMBC}^{\mathrm{b}, \mathrm{c}}$ & $\delta_{C}^{a}$ & $\delta_{\mathrm{H}}$, mult $(J \text { in } \mathrm{Hz})^{\mathrm{a}}$ & $\mathrm{HMBC}^{\mathrm{b}, \mathrm{c}}$ \\
\hline 1 & 170.4 & & & 169.9 & & \\
\hline 2 & 108.2 & & & 108.4 & & \\
\hline 3 & 200.8 & & & 201.0 & & \\
\hline 4 & 51.0 & & & 51.0 & & \\
\hline 5 & 36.6 & $1.66^{d}$ & $4,7,9,25$ & 36.4 & $1.68^{d}$ & $4,6,7,9,10,25$ \\
\hline $6 a x$ & 34.3 & $\begin{array}{c}\text { 1.34, ddd (12.0, 12.0 } \\
12.0)\end{array}$ & $5,7,10$ & 34.1 & $\begin{array}{c}1.20, \text { ddd }(11.9,11.9 \\
11.9)\end{array}$ & $5,7,8,10$ \\
\hline $6 e q$ & & 2.41, brd (12.0) & 7 & & $2.35^{d}$ & $5,7,8,10$ \\
\hline 7 & 77.4 & $3.74, \mathrm{dd}(12.0,4.3)$ & $5,6,8,26$ & 76.8 & $3.62, \mathrm{dd}(11.8,4.2)$ & $5,6,8,26$ \\
\hline 8 & 77.4 & & & 79.1 & & \\
\hline 9 & 80.5 & $3.21, d(11.2)$ & $5,7,8,10,11,26$ & 79.8 & $3.11, d(11.0)$ & $5,8,10,11,26$ \\
\hline 10 & 41.8 & $2.02^{d}$ & & 41.7 & $1.85^{d}$ & \\
\hline 11 & 124.5 & $5.85, d(10.0)$ & $5,9,13$ & 124.8 & $5.84, d(10.0)$ & $5,9,10,13$ \\
\hline 12 & 132.0 & $\begin{array}{c}5.61, \text { ddd }(10.0,5.3, \\
2.6)\end{array}$ & $4,10,13$ & 131.6 & $\begin{array}{c}5.60, \text { ddd }(10.0,5.1, \\
2.5)\end{array}$ & $4,10,13$ \\
\hline 13 & 39.4 & $2.81, \mathrm{~m}$ & $4,11,12,14,25$ & 39.4 & $2.79, \mathrm{~m}$ & $\begin{array}{c}4,5,11,12,14 \\
15,25\end{array}$ \\
\hline $14 a$ & 37.6 & $1.80^{\mathrm{d}}$ & $4,13,15,16$ & 37.6 & $1.80^{\mathrm{d}}$ & $4,13,15,16$ \\
\hline $14 b$ & & $1.98^{\mathrm{d}}$ & 16 & & $1.98^{\mathrm{d}}$ & 15,16 \\
\hline 15 & 137.5 & $5.49, \mathrm{dd}(14.7,11.5)$ & & 137.6 & $5.48, \mathrm{dd}(14.5,11.9)$ & \\
\hline 16 & 124.8 & $5.12, \mathrm{dd}(14.8,11.3)$ & & 124.8 & $5.12, \mathrm{dd}(14.8,11.6)$ & \\
\hline $17 a$ & 44.1 & $1.95^{\mathrm{d}}$ & 15,16 & 44.0 & $1.95^{d}$ & $15,16,18,19,23$ \\
\hline $17 b$ & & $2.32^{d}$ & $15,16,27$ & & $2.32^{d}$ & $15,16,19,27$ \\
\hline 18 & 40.8 & & & 40.7 & & \\
\hline 19 & 130.8 & $5.00, \mathrm{~s}$ & $17,18,23,28$ & 130.7 & $5.01, \mathrm{~s}$ & $17,18,21,23,28$ \\
\hline 20 & 135.1 & & & 135.1 & & \\
\hline 21 & 40.5 & $2.00^{d}$ & & 40.5 & $2.01^{d}$ & \\
\hline $22 a$ & 30.7 & $1.78^{d}$ & $\begin{array}{c}18,20,21,23,24, \\
29\end{array}$ & 30.7 & $1.79^{d}$ & $18,21,23,24,29$ \\
\hline $22 b$ & & $2.34^{d}$ & $18,21,29$ & & $2.34^{d}$ & 21,29 \\
\hline 23 & 87.9 & & & 88.0 & & \\
\hline 24 & 204.6 & & & 204.7 & & \\
\hline 25 & 16.6 & $1.60, \mathrm{~s}$ & $3,4,5,13$ & 16.6 & $1.59, \mathrm{~s}$ & $3,4,5,13$ \\
\hline 26 & 62.9 & $3.99, \mathrm{~s}$ & $7,8,9$ & 13.9 & $1.15, \mathrm{~s}$ & $7,8,9$ \\
\hline 27 & 24.4 & $1.24, \mathrm{~s}$ & $17,18,19,23$ & 24.3 & $1.25, \mathrm{~s}$ & $17,18,19,23$ \\
\hline 28 & 22.5 & $1.75, \mathrm{~s}$ & $19,20,21$ & 22.4 & $1.75, \mathrm{~s}$ & $19,20,21$ \\
\hline $29 a$ & 26.4 & $1.58^{d}$ & 22,30 & 26.4 & $1.62^{d}$ & $21,22,30$ \\
\hline $29 b$ & & $1.72^{d}$ & 30 & & $1.75^{\mathrm{d}}$ & $20,22,30$ \\
\hline 30 & 13.2 & $0.93, \mathrm{t}(7.4)$ & 21,29 & 13.1 & $0.93, \mathrm{t}(7.4)$ & 21,29 \\
\hline
\end{tabular}

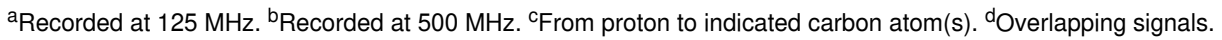

fused with another six-membered ring to give a dehydrodecalin core by the correlations from a singlet methyl hydrogen atom $\mathrm{H} 25$ to $\mathrm{C} 4, \mathrm{C} 5$, and $\mathrm{C} 13$. A series of HMBC correlations from two methyl singlets $\mathrm{H} 27$ and $\mathrm{H} 28$ elucidated the carbon connectivity of C23-C18-C19-C20-C21 (Figure 2), which was then coupled with the other COSY-defined fragment, C22/C21/C29/ $\mathrm{C} 30$, by the correlations from $\mathrm{H} 22$ to $\mathrm{C} 18$ and $\mathrm{C} 23$, yielding a cyclohexene ring. This ring was joined together with the dehydrodecalin moiety at the quaternary carbon atom $\mathrm{C} 18$ by HMBC correlations from $\mathrm{H} 17$ to $\mathrm{C} 18, \mathrm{C} 19$, and $\mathrm{C} 23$. As for the remaining four $\mathrm{sp}^{2}$ carbon atoms, $\mathrm{C} 1, \mathrm{C} 2, \mathrm{C} 3$, and $\mathrm{C} 24$, although only limited HMBC correlations H22/C24 and H25/C3 were available, a spirotetronate structure was assembled. This was in consideration of the high similarity of the ${ }^{13} \mathrm{C}$ NMR 
chemical shifts of these carbon atoms to those for the corresponding carbon atoms in $\mathbf{4}$ as well as due to the closeness of the UV spectral pattern between $\mathbf{1}$ and $\mathbf{4}$. The remaining four protons were finally assigned to hydroxy groups at $\mathrm{C} 7, \mathrm{C} 8, \mathrm{C} 9$, and $\mathrm{C} 26$ to complete the planar structure of $\mathbf{1}$. While $\mathbf{4}$ has an axial methyl group at $\mathrm{C} 8$ and equatorial hydroxy groups at $\mathrm{C} 7$ and $\mathrm{C} 9, \mathbf{1}$ has two additional hydroxy groups at C8 and $\mathrm{C} 26$. The axial orientation of the $\mathrm{C} 26$ hydroxymethyl group was supported by the ROESY correlations H26/H6ax and H26/H10 (Figure 3). The relative configuration of the remaining part was determined to be identical with $\mathbf{4}$ on the basis of ROESY correlations (Table S1, Supporting Information File 1) and ${ }^{3} J_{\mathrm{HH}}$ coupling constants [15]. The absolute configuration of $\mathbf{1}$ was deduced to be the same as $\mathbf{4}$ in consideration of the overall similarity of the electronic circular dichroism (ECD) spectra of 1 and 4 (Figure 4). This proposition was evidenced by the density functional theory (DFT) calculation of the ECD spectrum for $\mathbf{4}$ for which the absolute configuration was established by the modified Mosher's method in our previous work [15]. Since the acyltetronic acid exists as a mixture of keto-enol tautomers, the calculation was carried out using the four possible canonical structures of 4 (4a-d in Figure 5). The calculated ECD spectra of $\mathbf{4 a - d}$ and the one of $\mathbf{4}$, which includes all contributions from each tautomer according to the energy distribution, are shown in Figure 5 and Figure 4, respectively. The experimental ECD spectrum of $\mathbf{4}$, with positive and negative Cotton effects at 244 and $298 \mathrm{~nm}$, matched well with the calculated one of $\mathbf{4}$ (Figure 4). Noteworthy is that $\mathbf{4 a}$ and $\mathbf{4 b}$ (Tables S4-S7, Supporting Information File 1) have a lower free energy than $\mathbf{4 c}$

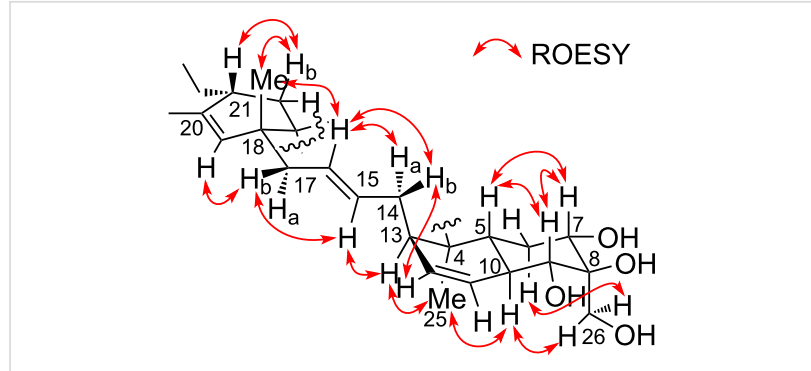

Figure 3: Relative configuration of 1 determined by ROESY analysis.

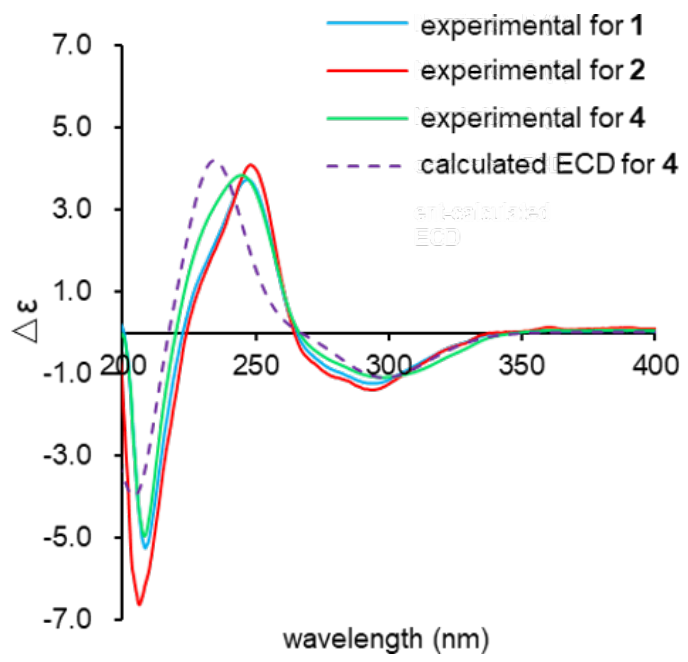

Figure 4: Experimental ECD spectra of 1, 2, and $\mathbf{4}$ and calculated ECD spectrum of 4.

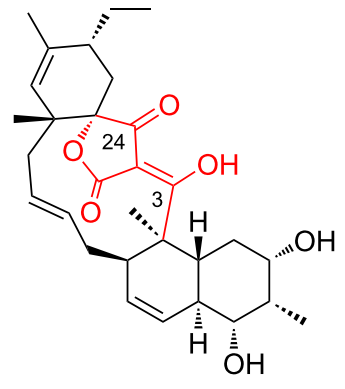

4a

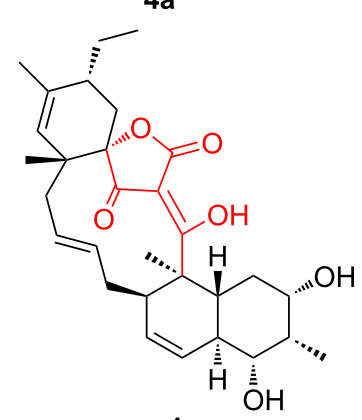

$4 c$

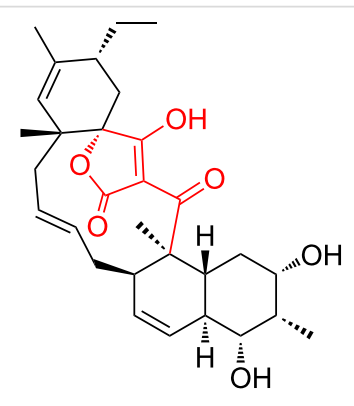

4b

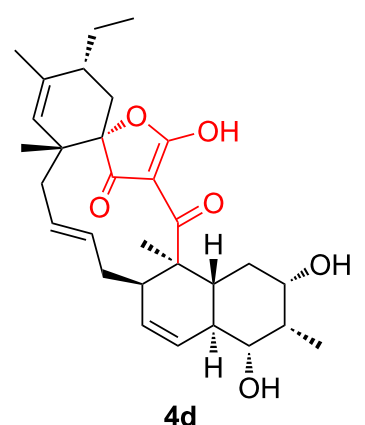

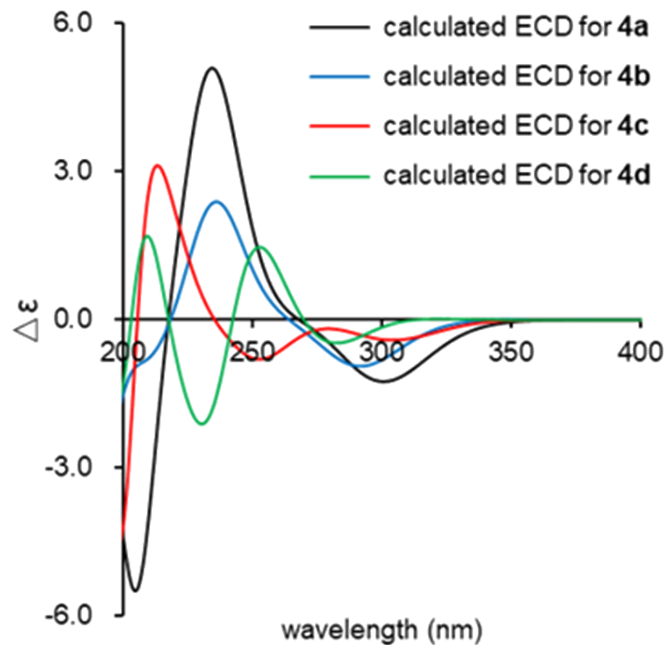

wavelength $(\mathrm{nm})$

Figure 5: Four tautomers $\mathbf{4 a - 4 d}$ of the tetronic acid moiety of $\mathbf{4}$ and calculated ECD spectra. 
and $\mathbf{4 d}$, and the calculated spectra for $\mathbf{4 a}$ and $\mathbf{4 b}$ are similar to the experimental one, indicating that $\mathbf{4 a}$ and $\mathbf{4 b}$ are the dominant tautomers in solution. This is the first validation to state that the keto carbonyl unit in the five-membered ring (C24 in Figure 5) and the acyl ketone connecting at C2 (C3 in Figure 5) are preferably enolized to form stable isomeric structures in spirotetronic acids.

The molecular formula of nomimicin $\mathrm{C}(\mathbf{2})$ was determined as $\mathrm{C}_{30} \mathrm{H}_{40} \mathrm{O}_{7}$ on the basis of HRESITOFMS data $\left([\mathrm{M}+\mathrm{Na}]^{+} \mathrm{m} / \mathrm{z}\right.$ $535.2665, \Delta-0.1 \mathrm{mmu}$ ), indicating that one oxygen atom (16 amu) was less compared to $\mathbf{1}$. This was consistent with the NMR spectra of $\mathbf{2}$ in which the resonances for the hydroxylated methylene moiety $\mathrm{H} 26 / \mathrm{C} 26\left(\delta_{\mathrm{H}} 3.99, \delta_{\mathrm{C}} 62.9\right)$ disappeared, and those for a shielded methyl group $\left(\delta_{\mathrm{H}} 1.15, \delta_{\mathrm{C}} 13.9\right)$ appeared instead, implying that the $\mathrm{C} 26$ hydroxymethyl group in $\mathbf{1}$ was replaced by a methyl group in 2 . HMBC correlations from $\mathrm{H} 26$ to $\mathrm{C} 7, \mathrm{C} 8$, and $\mathrm{C} 9$ and ROESY correlations between $\mathrm{H} 26$ and H10 supported the presence of a methyl group at C8 in an axial orientation (Figure S36, Supporting Information File 1). The remaining part of 2 was constructed based on COSY and HMBC analyses, and the relative configuration was established by NOESY/ROESY analyses (Table S2, Supporting Information File 1). The close similarity of ECD spectra between $\mathbf{1}$ and $\mathbf{2}$ was also indicative of the same absolute configuration of $\mathbf{2}$ and 4 (Figure 4).

The molecular formula of nomimicin D (3) was determined to be $\mathrm{C}_{30} \mathrm{H}_{42} \mathrm{O}_{6}$ through the HRESITOFMS analysis, which gave a sodium adduct ion $[\mathrm{M}+\mathrm{Na}]^{+}$at $m / z 519.2717(\Delta 0.0 \mathrm{mmu})$. Analysis of ${ }^{1} \mathrm{H}$ NMR, ${ }^{13} \mathrm{C}$ NMR, and HSQC spectra revealed the presence of four oxygenated $\mathrm{sp}^{2}$ carbon atoms, three nonprotonated $\mathrm{sp}^{2}$ carbon atoms, $\mathrm{six} \mathrm{sp}^{2}$ methine groups, one $\mathrm{sp}^{2}$ methylene unit, one quaternary carbon atom, $\mathrm{six}^{3} \mathrm{sp}^{3}$ methine groups (two are oxygenated), four $\mathrm{sp}^{3}$ methylene units, and five $\mathrm{sp}^{3}$ methyl groups (Table 2). A sequence of COSY correlations from the doublet methyl proton $\mathrm{H} 26$ to an oxymethine proton $\mathrm{H} 7$ via an oxymethine proton $\mathrm{H} 9$, together with HMBC correlations from $\mathrm{H} 26$ and $\mathrm{H} 8$ to $\mathrm{C} 7$ and $\mathrm{H} 8$ to $\mathrm{C} 6$, gave an oxygenated cyclohexane ring with a methyl substitution (Figure 6). COSY correlations were extended from H10 to a methylene proton $\mathrm{H} 17$, providing a carbon chain containing double bonds at $\mathrm{C} 11 / \mathrm{C} 12$ and $\mathrm{C} 15 / \mathrm{C} 16$. HMBC correlations from a singlet methyl hydrogen atom $\mathrm{H} 25$ to $\mathrm{C} 4, \mathrm{C} 5$, and $\mathrm{C} 13$ indicated closure of another cyclohexane ring, and thus a dehydrodecalin core with a side chain at $\mathrm{C} 13$ was established. The chain was further extended from $\mathrm{H} 17$ to the terminal methyl proton $\mathrm{H} 30$ by COSY correlations for $\mathrm{H} 21 / \mathrm{H} 29 / \mathrm{H} 30$ and a series of HMBC correlations from two allylic methyl hydrogen atoms $\mathrm{H} 27$ and $\mathrm{H} 28$ to the carbon atoms within a three-bond length (Figure 6). The remaining five nonprotonated carbon atoms, $\mathrm{C} 1\left(\delta_{\mathrm{C}} 174.5\right), \mathrm{C} 2\left(\delta_{\mathrm{C}} 99.5\right), \mathrm{C} 3\left(\delta_{\mathrm{C}} 203.2\right), \mathrm{C} 23\left(\delta_{\mathrm{C}}\right.$ $155.7)$, and $\mathrm{C} 24\left(\delta_{\mathrm{C}} 180.7\right)$ and the exo-methylene group (H22: $\left.\delta_{\mathrm{H}} 4.66 / 5.00 ; \mathrm{C} 22: \delta_{\mathrm{C}} 88.7\right)$ were assigned to the tetronic acid moiety based on the following considerations. First, the ${ }^{13} \mathrm{C}$ chemical shift values of these six carbon atoms were closely similar to those for the tetronic acid bearing an exo-methylene substituent in known natural products [16-18]. Secondly, the UV spectrum of $\mathbf{3}$, showing absorption maxima at 243 and $302 \mathrm{~nm}$, was matched well with that for ecteinamycin, which possesses the exo-methylene-substituted tetronic acid moiety [19]. This assignment was supported by correlations from $\mathrm{H} 22$ to $\mathrm{C} 23, \mathrm{C} 24$, and $\mathrm{C} 2$ and from $\mathrm{H} 25$ to $\mathrm{C} 3$, though not all the carbon-carbon connectivities were proven by HMBC analysis.

The relative configuration of $\mathbf{3}$ was elucidated by analyzing the NOESY spectrum (Table S3, Supporting Information File 1). Correlations for $\mathrm{H} 5 / \mathrm{H} 7, \mathrm{H} 5 / \mathrm{H} 9$, and $\mathrm{H} 7 / \mathrm{H} 9$ and large scalar couplings $\left({ }^{3} J_{\mathrm{HH}}>10 \mathrm{~Hz}\right)$ for $\mathrm{H} 5 / \mathrm{H} 6 \mathrm{ax}, \mathrm{H} 6 \mathrm{ax} / \mathrm{H} 7$, and $\mathrm{H} 5 / \mathrm{H} 9$ established the trans-ring fusion of the dehydrodecalin moiety. The axial orientation of the methyl group at $\mathrm{C} 8$ was evidenced by NOESY correlations H26/H6ax and H26/H10. Correlations of $\mathrm{H} 25 / \mathrm{H} 10$ and $\mathrm{H} 25 / \mathrm{H} 13$ placed the $\mathrm{H} 25$ methyl proton and $\mathrm{H} 13$ on the same side of the dehydrodecalin ring at the $\mathrm{H} 9$ axial proton. The geometries of the double bonds at C15/C16, C18/ $\mathrm{C} 19$, and $\mathrm{C} 20 / \mathrm{C} 21$ were assigned as $E$, based on the NOESY correlations H13/H15, H14/H16, H15/H17, H17/H19, and H28/ $\mathrm{H} 29$ (Figure 7). The s-cis configuration of the diene moiety was indicated by a NOESY correlation between $\mathrm{H} 21$ and H27. The absolute configuration of the dehydrodecalin moiety of $\mathbf{3}$ was tentatively assigned to be identical with $\mathbf{4}$ because 3 was considered as a biosynthetic precursor of 4 [20].

Compounds 1-3 showed antimicrobial activity against Kocuria rhizopila with a MIC value of $6.5 \mu \mathrm{g} / \mathrm{mL}$ and $\mathbf{1}$ and $\mathbf{2}$ were also active against Bacillus subtilis with a MIC value of $12.5 \mu \mathrm{g} / \mathrm{mL}$. Compounds 1-3 were inactive against Staphylococcus aureus, Ralstonia solanacearum, Rhizobium radiobacter, and Candida albicans. In addition, $\mathbf{1}$ and $\mathbf{2}$ exhibited cytotoxicity against P388 murine leukemia cells with $\mathrm{IC}_{50}$ of 33 and $89 \mu \mathrm{M}$, respectively.

\section{Conclusion}

In summary, UV-based chemical screening of bioactive compounds from marine-derived actinomycetes led to the discovery of three new polyketides, nomimicins B (1), C (2), and D (3) along with a known congener, nomimicin A (4), from Actinomadura sp. AKA43. Compounds $\mathbf{1}$ and $\mathbf{2}$ are new members of the spirotetronate-class antibiotics, characterized by a macrocyclic structure containing a trans-decalin unit and a tetronic acid moiety spiro-linked with a cyclohexene ring. To date, more than 100 compounds [21,22], including tetrocarcin [23] and 
Table 2: ${ }^{1} \mathrm{H}$ and ${ }^{13} \mathrm{C}$ NMR data for nomimicin $\mathrm{D}(\mathbf{3})$.

\begin{tabular}{|c|c|c|c|}
\hline \multirow[b]{2}{*}{ no. } & \multicolumn{3}{|c|}{ nomimicin D (3) } \\
\hline & $\delta_{C}^{a}$ & $\delta_{\mathrm{H}}$, mult $(\mathrm{J} \text { in } \mathrm{Hz})^{\mathrm{b}}$ & $\mathrm{HMBC}^{\mathrm{b}, \mathrm{c}}$ \\
\hline 1 & 174.5 & & \\
\hline 2 & 99.5 & & \\
\hline 3 & 203.2 & & \\
\hline 4 & 52.8 & & \\
\hline 5 & 36.5 & $1.72^{\mathrm{d}}$ & $4,7,9,11,25$ \\
\hline $6 a x$ & 30.8 & 1.14, ddd $(11.7,11.7,11.7)$ & $4,5,7,8,10$ \\
\hline $6 e q$ & & 1.80, brd (11.7) & 7 \\
\hline 7 & 72.3 & 3.83, ddd $(11.6,4.5,4.5)$ & 26 \\
\hline 8 & 43.4 & $2.32, \mathrm{~m}$ & $7,9,10,26$ \\
\hline 9 & 75.5 & $3.40, \mathrm{dd}(10.8,4.7)$ & $5,10,11,26$ \\
\hline 10 & 38.9 & $1.94^{\mathrm{d}}$ & 9,11 \\
\hline 11 & 125.8 & $5.85, d(10.2)$ & $5,9,10,12,13$ \\
\hline 12 & 131.5 & 5.72, ddd $(10.2,4.8,2.5)$ & $4,13,14$ \\
\hline 13 & 41.5 & $3.32^{d}$ & $4,5,14$ \\
\hline $14 a$ & 38.7 & $1.75^{\mathrm{d}}$ & $12,13,15,16$ \\
\hline $14 b$ & & $2.00^{d}$ & $12,13,15,16$ \\
\hline 15 & 131.8 & $5.40, \mathrm{dt}(15.0,7.2)$ & $14,16,17$ \\
\hline 16 & 130.7 & $5.26, \mathrm{dt}(15.2,7.0)$ & $14,15,17$ \\
\hline 17 & 44.9 & 2.63, d (6.9) & $15,16,18,19,27$ \\
\hline 18 & 135.6 & & \\
\hline 19 & 130.5 & $5.59, \mathrm{~s}$ & $17,21,27,28$ \\
\hline 20 & 133.5 & & \\
\hline 21 & 131.9 & $5.20, \mathrm{t}(7.3)$ & $19,29,26$ \\
\hline $22 a$ & 88.7 & $4.66, d(1.5)$ & $2,23,24$ \\
\hline $22 b$ & & $5.00, d(1.5)$ & 23,24 \\
\hline 23 & 155.7 & & \\
\hline 24 & 180.7 & & \\
\hline 25 & 16.0 & $1.38, \mathrm{~s}$ & $3,4,5,13$ \\
\hline 26 & 6.1 & $0.92, \mathrm{~d}(6.9)$ & $7,8,9$ \\
\hline 27 & 18.2 & $1.69, \mathrm{~s}$ & $17,18,19$ \\
\hline 28 & 17.2 & $1.67, \mathrm{~s}$ & $19,20,21$ \\
\hline 29 & 22.5 & 2.08, q (7.5) & $20,21,30$ \\
\hline 30 & 14.8 & $0.98, \mathrm{t}(7.5)$ & 21,29 \\
\hline
\end{tabular}

aRecorded at $125 \mathrm{MHz}$. ${ }^{\mathrm{b}}$ Recorded at $500 \mathrm{MHz}$. ${ }^{\mathrm{C}}$ From proton to indicated carbon atom(s). ${ }^{\mathrm{d} O v e r l a p p i n g ~ s i g n a l s . ~}$

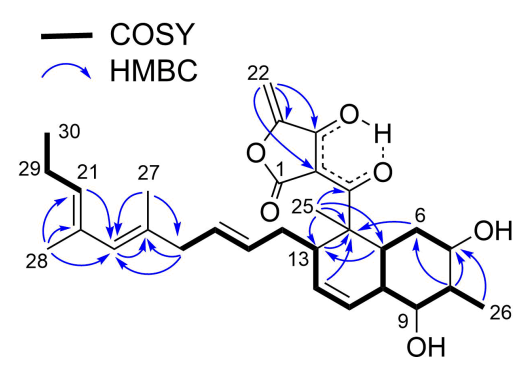

Figure 6: COSY and key HMBC correlations for 3.

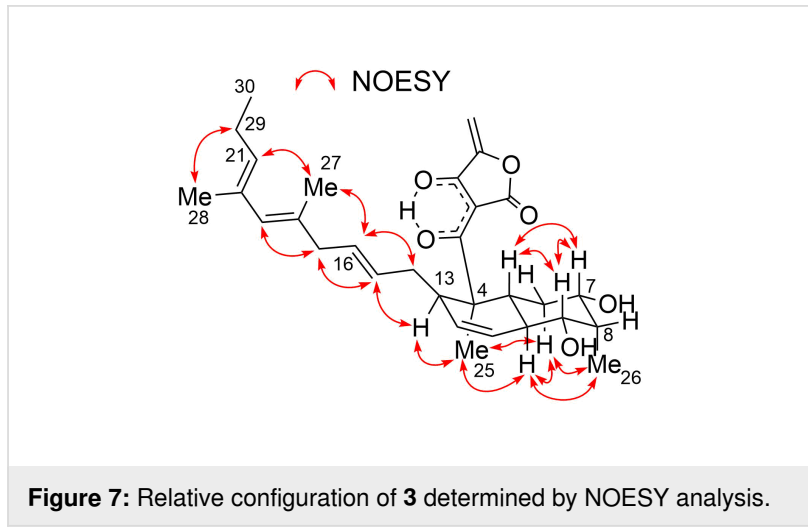


kijanimicin [24], are known within the spirotetronate class. Of these, nomimicins A-C $(\mathbf{4}, \mathbf{1}$, and $\mathbf{2})$ are featured by the smallest macrocyclic ring and highly oxygenated dehydrodecalin moiety. Spirotetronates are known to be constructed by the intramolecular Diels-Alder reaction [20,25]. Compound $\mathbf{3}$ is very likely a biosynthetic precursor of 4 . This is the first report on the isolation of a biosynthetic precursor of spirotetronate antibiotics as an innate metabolite from a wild-type strain, while such an intermediate was previously obtained from a genetically engineered strain [26].

\section{Experimental}

\section{General experimental procedures}

Optical rotations were measured using a JASCO DIP-3000 polarimeter. ECD spectra were recorded on a JASCO J-720W spectropolarimeter. UV and IR spectra were recorded on a Shimadzu UV-1800 spectrophotometer and on a PerkinElmer Spectrum 100, respectively. All NMR experiments were performed on a Bruker AVANCE 500 spectrometer in $\mathrm{CD}_{3} \mathrm{OD}$ using the residual solvent proton $\left(\delta_{\mathrm{H}} 3.31\right)$ and carbon $\left(\delta_{\mathrm{C}} 49.2\right)$ signals as internal standards. HRESITOFMS were recorded on a Bruker micrOTOF focus mass spectrometer. An Agilent HP1200 system equipped with a diode array detector was used for analysis and purification. The computational study was performed using MacroModel implemented in the Maestro 12.3 software package [27] and the Gaussian16, Revision C.01 program [28]. A part of these computations was conducted using the SuperComputer System, Institute for Chemical Research, Kyoto University. Molecular structures were visualized using Maestro 12.3 software package. ECD spectra were visualized using GaussView 6.0.16 and Microsoft Excel 2019.

\section{Microorganism}

Actinomadura sp. AKA43 was isolated from a sea water sample collected from Sagami Bay at a depth of $-800 \mathrm{~m}$ at the IzuAkazawa DSW pumping station in Shizuoka, Japan, as previously reported [13]. The isolated strain was identified as a member of the genus Actinomadura on the basis of $100 \%$ similarity in the 16S rRNA gene sequence (1397 nucleotides, DDBJ accession number LC498623) with Actinomadura geliboluensis A8036 ${ }^{\mathrm{T}}$ (DDBJ accession number HQ157187).

\section{Fermentation}

Actinomadura sp. AKA43 cultured on Bn-2 agar medium (soluble starch $0.5 \%$, glucose $0.5 \%$, meat extract (Kyokuto Pharmaceutical Industrial Co., Ltd.) $0.1 \%$, yeast extract (Difco Laboratories) $0.1 \%$, NZ-case (Wako Chemicals USA, Inc.) $0.2 \%, \mathrm{NaCl} 0.2 \%, \mathrm{CaCO}_{3} 0.1 \%$, and agar $1.5 \%$ in distilled water of $\mathrm{pH}$ 7.0) was inoculated into a $500 \mathrm{~mL} \mathrm{~K}-1$ flask containing $100 \mathrm{~mL}$ of the $\mathrm{V}-22$ seed medium (soluble starch $1 \%$, glucose $0.5 \%$, NZ-case $0.3 \%$, yeast extract $0.2 \%$, tryptone
(Difco Laboratories) $0.5 \%, \mathrm{~K}_{2} \mathrm{HPO}_{4} 0.1 \%, \mathrm{MgSO}_{4} \cdot 7 \mathrm{H}_{2} \mathrm{O}$ $0.05 \%$, and $\mathrm{CaCO}_{3} 0.3 \%$ in distilled water of $\mathrm{pH} 7.0$ ). The flask was shaken on a rotary shaker $(200 \mathrm{rpm})$ at $30{ }^{\circ} \mathrm{C}$ for 4 days. For the production of nomimicins B (1) and C (2), the seed culture $(3 \mathrm{~mL})$ was transferred into $20500 \mathrm{~mL} \mathrm{~K}-1$ flasks, each containing $100 \mathrm{~mL}$ of the A16 production medium (glucose $2 \%$, Pharmamedia (Traders Protein) $1 \%, \mathrm{CaCO}_{3} 0.5 \%$, and Diaion ${ }^{\circledR}$ HP-20 (Mitsubishi Chemical Corporation) $1 \%$ in distilled water of $\mathrm{pH}$ 7.0). The inoculated flasks were placed on a rotary shaker (200 rpm) at $30{ }^{\circ} \mathrm{C}$ for 7 days. For the production of nomimicin $\mathrm{D}(3)$, the seed culture $(3 \mathrm{~mL})$ was transferred into $20500 \mathrm{~mL}$ $\mathrm{K}-1$ flasks, each containing $100 \mathrm{~mL}$ of the $\mathrm{A} 11 \mathrm{M}$ production medium (glucose $0.2 \%$, soluble starch $2.5 \%$, yeast extract $0.5 \%$, polypeptone (Wako Pure Chemical Industries, Ltd.) 0.5\%, NZ-amine (Wako Pure Chemical Industries, Ltd.) $0.5 \%, \mathrm{CaCO}_{3}$ $0.5 \%$, and Diaion ${ }^{\circledR} \mathrm{HP}-201 \%$ in distilled water of $\left.\mathrm{pH} 7.0\right)$. The inoculated flasks were placed on a rotary shaker $(200 \mathrm{rpm})$ at $30{ }^{\circ} \mathrm{C}$ for 7 days.

\section{Isolation}

At the end of the fermentation period, $100 \mathrm{~mL}$ of 1-butanol was added to each flask, and the flasks were agitated on a rotary shaker for $1 \mathrm{~h}$. The mixture was centrifuged at 6,000 rpm for $10 \mathrm{~min}$, and the organic layer was separated from the aqueous layer containing the mycelium. Evaporation of the solvent gave $3.8 \mathrm{~g}$ of extract from $2 \mathrm{~L}$ of A16 culture. The extract was subjected to silica gel column chromatography with a step gradient of $\mathrm{CHCl}_{3} / \mathrm{MeOH}(1: 0,20: 1,10: 1,4: 1,2: 1,1: 1$, and 0:1, v/v). Fraction 4 (4:1) was concentrated to give $0.23 \mathrm{~g}$ of brown oil that was further purified by preparative HPLC (Cosmosil 5C18ARII, $10 \times 250 \mathrm{~mm}, 4 \mathrm{~mL} / \mathrm{min}$, UV detection at $254 \mathrm{~nm}$ ) with $73 \% \mathrm{MeCN}$ in $0.1 \% \mathrm{HCO}_{2} \mathrm{H}$ solution to yield nomimicin $\mathrm{A}(\mathbf{4}$, $\left.33 \mathrm{mg}, t_{\mathrm{R}} 21.5 \mathrm{~min}\right)$. Fractions 5 (2:1) and 6 (1:1) were combined and concentrated to provide $0.48 \mathrm{~g}$ of brown oil that was then fractionated by ODS column chromatography with a gradient of $\mathrm{MeCN}+0.1 \% \mathrm{HCO}_{2} \mathrm{H}$ solution (2:8, 3:7, 4:6, 5:5, $6: 4,7: 3$, and $8: 2, \mathrm{v} / \mathrm{v})$. The ODS fraction $6(7: 3)$ was concentrated to afford $0.22 \mathrm{~g}$ of semipure material. Final purification was achieved by preparative HPLC (Cosmosil 5C18-ARII, $10 \times 250 \mathrm{~mm}, 4 \mathrm{~mL} / \mathrm{min}$, UV detection at $254 \mathrm{~nm}$ ) with $52 \%$ $\mathrm{MeCN}$ in $0.1 \% \mathrm{HCO}_{2} \mathrm{H}$ solution to yield nomimicin $\mathrm{B}(\mathbf{1}$, $\left.16.1 \mathrm{mg}, t_{\mathrm{R}} 19.5 \mathrm{~min}\right)$ and nomimicin $\mathrm{C}(2,12.2 \mathrm{mg}$, $t_{\mathrm{R}} 21.5 \mathrm{~min}$ ). Similarly, evaporation of the solvent gave $3.0 \mathrm{~g}$ of extract from $2 \mathrm{~L}$ of $\mathrm{A} 11 \mathrm{M}$ culture. The extract was subjected to silica gel column chromatography with a gradient of $\mathrm{CHCl}_{3}$ / $\mathrm{MeOH}(1: 0,20: 1,10: 1,4: 1,2: 1,1: 1$, and 0:1, v/v). Fraction 7 $(0: 1)$ was concentrated to give $0.37 \mathrm{~g}$ of brown oil, which was then fractionated by ODS column chromatography with a gradient of $\mathrm{MeCN}+0.1 \% \mathrm{HCO}_{2} \mathrm{H}$ solution (2:8, 3:7, 4:6, 5:5, $6: 4,7: 3$, and $8: 2, \mathrm{v} / \mathrm{v})$. The ODS fraction $5(6: 4)$ was concentrated to give $72.6 \mathrm{mg}$ of semipure material. Final purification 
using preparative HPLC (Cosmosil XTerra Prep RP18, $10 \times 250 \mathrm{~mm}, 4 \mathrm{~mL} / \mathrm{min}$, UV detection at $254 \mathrm{~nm}$ ) with $38 \%$ $\mathrm{MeCN}$ in $10 \mathrm{mM} \mathrm{NH}_{4} \mathrm{HCO}_{3}$ solution yielded nomimicin D (3, $6.0 \mathrm{mg}, t_{\mathrm{R}} 30.5 \mathrm{~min}$ ).

\section{Nomimicin B (1)}

Colorless amorphous solid; $[\alpha]_{\mathrm{D}}{ }^{23}-29(c 0.10, \mathrm{MeOH})$; UV $(\mathrm{MeOH}) \lambda_{\max }(\log \varepsilon) 246$ (3.83), $293 \mathrm{~nm}$ (3.71); ECD (c $\left.9.5 \times 10^{-5}, \mathrm{MeOH}\right) \lambda_{\text {ext }}(\Delta \varepsilon) 208(-5.27), 247(+3.72), 294 \mathrm{~nm}$ $(-1.24)$; IR $v_{\max }: 3360,2965,1755,1619,1408,1088$, $998 \mathrm{~cm}^{-1}$; see Table 1 for ${ }^{1} \mathrm{H}$ and ${ }^{13} \mathrm{C}$ NMR data; HRESITOFMS $(\mathrm{m} / \mathrm{z}):[\mathrm{M}+\mathrm{Na}]^{+}$calcd for $\mathrm{C}_{30} \mathrm{H}_{40} \mathrm{O}_{8} \mathrm{Na}$, 551.2615; found, 551.2612.

\section{Nomimicin C (2)}

Colorless amorphous solid; $[\alpha]_{\mathrm{D}}^{23}-12(c 0.10, \mathrm{MeOH})$; UV $(\mathrm{MeOH}) \lambda_{\max }(\log \varepsilon) 246$ (3.93), $292 \mathrm{~nm}$ (3.78); ECD (c $\left.9.7 \times 10^{-5}, \mathrm{MeOH}\right) \lambda_{\text {ext }}(\Delta \varepsilon) 208(-6.63), 246(+4.08), 298 \mathrm{~nm}$ $(-1.39)$; IR $v_{\max }: 3380,2963,1744,1618,1404,1097$, $1007 \mathrm{~cm}^{-1}$; see Table 1 for ${ }^{1} \mathrm{H}$ and ${ }^{13} \mathrm{C}$ NMR data; HRESITOFMS $(m / z):[\mathrm{M}+\mathrm{Na}]^{+}$calcd for $\mathrm{C}_{30} \mathrm{H}_{40} \mathrm{O}_{7} \mathrm{Na}$, 535.2666; found, 535.2665.

\section{Nomimicin D (3)}

Colorless amorphous solid; $[\alpha]_{\mathrm{D}}{ }^{23}-70(c 0.10$. MeOH); UV $(\mathrm{MeOH}) \lambda_{\max }(\log \varepsilon) 243$ (3.99), $302 \mathrm{~nm}$ (3.54); IR $v_{\text {max }}: 3380$, 2963, 1723, 1619, 1413, 1258, $1010 \mathrm{~cm}^{-1}$; see Table 2 for ${ }^{1} \mathrm{H}$ and ${ }^{13} \mathrm{C}$ NMR data; HRESITOFMS $(\mathrm{m} / \mathrm{z}):[\mathrm{M}+\mathrm{Na}]^{+}$calcd for $\mathrm{C}_{30} \mathrm{H}_{40} \mathrm{O}_{6} \mathrm{Na}, 519.2717$; found, 519.2717.

\section{Nomimicin A (4)}

Colorless amorphous solid; $[\alpha]_{\mathrm{D}}{ }^{23}-87$ (c $0.10 . \mathrm{CHCl}_{3}$, lit. $\left.[\alpha]_{\mathrm{D}}^{23}-94\left(c 0.10 . \mathrm{CHCl}_{3}\right)[15]\right) ; \mathrm{UV}(\mathrm{MeOH}) \lambda_{\max }(\log \varepsilon) 242$ (3.73), $298 \mathrm{~nm}$ (3.59); ECD $\left(c 1.0 \times 10^{-4}, \mathrm{MeOH}\right) \lambda_{\text {ext }}(\Delta \varepsilon) 208$ (-4.98), 244 (+3.85), $298 \mathrm{~nm}(-1.09)$; IR $v_{\max }$ : 3348, 2938, 1735, 1620, 1435, $997 \mathrm{~cm}^{-1}$; HRESITOFMS $(\mathrm{m} / \mathrm{z}):[\mathrm{M}+\mathrm{Na}]^{+}$ calcd for $\mathrm{C}_{30} \mathrm{H}_{40} \mathrm{O}_{6} \mathrm{Na}, 519.2717$; found, 519.2722.

\section{ECD calculations}

The conformational sampling of structure $\mathbf{4 a}$ was performed by applying 100,000 steps of the Monte Carlo Multiple Minimum (MCMM) method with PRCG energy minimization by the OPLS3e force field to obtain 56 conformational isomers within $10.0 \mathrm{kcal} / \mathrm{mol}$ from the minimum energy conformer. Geometries of the conformers were then optimized at the M06-2X/6$31 \mathrm{G}(\mathrm{d})$ level of theory with the SMD solvation model. Frequency calculations were carried out at the same level of theory to confirm the absence of imaginary frequencies and obtain thermal corrections for the Gibbs free energy. After eliminating duplicated structures with the threshold of $0.01 \AA$ RMSD, the single-point energy was calculated at the M06-2X/def2-TZVP-
SMD level of theory, affording 24 conformers within $3.0 \mathrm{kcal} / \mathrm{mol}$ from the minimum Gibbs free energy. The ECD spectrum of each conformer was simulated by the TDDFT calculation of 25 excited states at the $\omega$ B97X-D/def2-TZVPPCM level of theory. The spectrum of structure $4 a$ was created by the weighted average of the above-obtained spectra (halfwidth: $0.29 \mathrm{eV}$ ) according to the Boltzmann distribution, corrected by a red-shift of $15 \mathrm{~nm}$, and scaled to adjust the strength of the vertical axis. The spectra of structures $\mathbf{4 b}, \mathbf{4 c}$, and 4d were similarly simulated using 122, 126, and 475 OPLS3e-minimized structures and 26, 22, and 31 DFT-optimized structures, respectively. The spectrum of $\mathbf{4}$ was created using the weighted average of the spectra of all low-lying conformers of $\mathbf{4 a - d}$ according to the respective Boltzmann distribution. The Cartesian coordinates and the energies of the most stable conformers for each tautomer are included in Supporting Information File 1.

\section{Biological assays}

Antimicrobial activity and cytotoxicity were evaluated according to the procedures previously described [29].

\section{Supporting Information}

\section{Supporting Information File 1}

Copies of UV, IR, and NMR spectra for $\mathbf{1 - 4}$ as well as

Cartesian coordinates and energies of the most stable conformers of $\mathbf{4 a}-\mathbf{d}$.

[https://www.beilstein-journals.org/bjoc/content/ supplementary/1860-5397-17-141-S1.pdf]

\section{Acknowledgements}

The authors are in debt to Prof. Yasufumi Hikichi and Dr. Ayami Kanda at Kochi University for providing $R$. solanacearum SUPP1541. P388 cells were obtained from JCRB Cell Bank under an accession code JCRB0017 (Lot. 06252002).

\section{ORCID ${ }^{\circledR}$ iDs}

Zhiwei Zhang - https://orcid.org/0000-0003-2238-5426 Tao Zhou - https://orcid.org/0000-0002-6359-2598 Taehui Yang - https://orcid.org/0000-0002-7374-3281 Keisuke Fukaya - https://orcid.org/0000-0002-7148-4714 Shun Saito - https://orcid.org/0000-0001-9270-4272

\section{References}

1. Bérdy, J. J. Antibiot. 2005, 58, 1-26. doi:10.1038/ja.2005.1

2. Lam, K. S. Curr. Opin. Microbiol. 2006, 9, 245-251. doi:10.1016/j.mib.2006.03.004 
3. Sayed, A. M.; Hassan, M. H. A.; Alhadrami, H. A.; Hassan, H. M.; Goodfellow, M.; Rateb, M. E. J. Appl. Microbiol. 2020, 128, 630-657. doi:10.1111/jam.14386

4. ul Hassan, S. S.; Shaikh, A. L. Biomed. Pharmacother. 2017, 87, 46-57. doi:10.1016/j.biopha.2016.12.086

5. Manivasagan, P.; Venkatesan, J.; Sivakumar, K.; Kim, S.-K. Microbiol. Res. 2014, 169, 262-278. doi:10.1016/j.micres.2013.07.014

6. Blunt, J. W.; Copp, B. R.; Keyzers, R. A.; Munro, M. H. G.; Prinsep, M. R. Nat. Prod. Rep. 2017, 34, 235-294. doi:10.1039/c6np00124f

7. Abdelmohsen, U. R.; Bayer, K.; Hentschel, U. Nat. Prod. Rep. 2014, 31, 381-399. doi:10.1039/c3np70111e

8. Wang, C.; Lu, Y.; Cao, S. Arch. Pharmacal Res. 2020, 43, 677-704. doi:10.1007/s12272-020-01251-0

9. Furumai, T.; Eto, K.; Sasaki, T.; Higuchi, H.; Onaka, H.; Saito, N.; Fujita, T.; Naoki, H.; Igarashi, Y. J. Antibiot. 2002, 55, 873-880. doi:10.7164/antibiotics.55.873

10. Igarashi, Y.; Ikeda, M.; Miyanaga, S.; Kasai, H.; Shizuri, Y.; Matsuura, N. J. Antibiot. 2015, 68, 345-347. doi:10.1038/ja.2014.151

11. Karim, M. R. U.; In, Y.; Zhou, T.; Harunari, E.; Oku, N.; Igarashi, Y. Org. Lett. 2021, 23, 2109-2113. doi:10.1021/acs.orglett.1c00210

12. Yang, T.; Yamada, K.; Nakayama, J.; Igarashi, Y.; Terahara, T.; Kobayashi, T.; Imada, C. Deep Ocean Water Res. 2019, 19, 137-146. doi:10.11174/dowas.19.137

13. Yang, T.; Yamada, K.; Zhou, T.; Harunari, E.; Igarashi, Y.; Terahara, T.; Kobayashi, T.; Imada, C. J. Antibiot. 2019, 72, 202-209. doi:10.1038/s41429-018-0139-7

14. Igarashi, Y.; Matsuyuki, Y.; Yamada, M.; Fujihara, N.; Harunari, E.; Oku, N.; Karim, M. R. U.; Yang, T.; Yamada, K.; Imada, C.; Fukaya, K.; Urabe, D. J. Org. Chem. 2021, 86, 6528-6537. doi:10.1021/acs.joc.1c00358

15. Igarashi, Y.; lida, T.; Oku, N.; Watanabe, H.; Furihata, K.; Miyanouchi, K. J. Antibiot. 2012, 65, 355-359. doi:10.1038/ja.2012.30

16. Terui, Y.; Sakazaki, R.; Shoji, J. J. Antibiot. 1990, 43, 1245-1253. doi:10.7164/antibiotics.43.1245

17. Keller-Juslén, C.; King, H. D.; Kuhn, M.; Loosli, H. R.; Pache, W.; Petcher, T. J.; Weber, H. P.; von Wartburg, A. J. Antibiot. 1982, 35 142-150. doi:10.7164/antibiotics.35.142

18. Hatsu, M.; Sasaki, T.; Miyadoh, S.; Watabe, H.; Takeuchi, Y.; Kodama, Y.; Orikasa, Y.; Kajii, K.; Shomura, T.; Yamamoto, H.; Sezaki, M.; Inouye, S.; Kondo, S. J. Antibiot. 1990, 43, 259-266. doi:10.7164/antibiotics.43.259

19. Igarashi, Y.; Matsuoka, N.; In, Y.; Kataura, T.; Tashiro, E.; Saiki, I.; Sudoh, Y.; Duangmal, K.; Thamchaipenet, A. Org. Lett. 2017, 19, 1406-1409. doi:10.1021/acs.orglett.7b00318

20. Hashimoto, T.; Hashimoto, J.; Teruya, K.; Hirano, T.; Shin-ya, K.; Ikeda, H.; Liu, H.-w.; Nishiyama, M.; Kuzuyama, T. J. Am. Chem. Soc. 2015, 137, 572-575. doi:10.1021/ja510711x

21. Lacoske, M. H.; Theodorakis, E. A. J. Nat. Prod. 2015, 78, 562-575. doi:10.1021/np500757w

22. Braddock, A. A.; Theodorakis, E. A. Mar. Drugs 2019, 17, 232. doi:10.3390/md17040232

23. Tomita, F.; Tamaoki, T.; Shirahata, K.; Kasai, M.; Morimoto, M.; Ohkubo, S.; Mineura, K.; Ishii, S. J. Antibiot. 1980, 33, 668-670. doi:10.7164/antibiotics.33.668

24. Mallams, A. K.; Puar, M. S.; Rossman, R. R.; McPhail, A. T.; Macfarlane, R. D. J. Am. Chem. Soc. 1981, 103, 3940-3943. doi:10.1021/ja00403a063
25. Zhang, H.; White-Phillip, J. A.; Melançon, C. E., III; Kwon, H.-j.; Yu, W.-I.; Liu, H.-w. J. Am. Chem. Soc. 2007, 129, 14670-14683. doi:10.1021/ja0744854

26. Jeon, B.-s.; Wang, S.-A.; Ruszczycky, M. W.; Liu, H.-w. Chem. Rev. 2017, 117, 5367-5388. doi:10.1021/acs.chemrev.6b00578

27. MacroModel; Schrödinger, LLC: New York, NY, USA, 2020.

28. Gaussian 16, Revision C.01; Gaussian, Inc.: Wallingford, CT, USA, 2016.

29. Karim, M. R. U.; Harunari, E.; Oku, N.; Akasaka, K.; Igarashi, Y. J. Nat. Prod. 2020, 83, 1295-1299. doi:10.1021/acs.jnatprod.0c00082

\section{License and Terms}

This is an Open Access article under the terms of the Creative Commons Attribution License (https://creativecommons.org/licenses/by/4.0). Please note that the reuse, redistribution and reproduction in particular requires that the author(s) and source are credited and that individual graphics may be subject to special legal provisions.

The license is subject to the Beilstein Journal of Organic Chemistry terms and conditions: (https://www.beilstein-journals.org/bjoc/terms)

The definitive version of this article is the electronic one which can be found at: https://doi.org/10.3762/bjoc.17.141 